\title{
La perspectiva pragmática del texto autobiográfico. Cuando el diario se convierte en autobiografía: Sibilla Aleramo
}

Mercedes Arriaga Flórez

Dentro del panorama de la literatura italiana contemporánea, pocos autores como Sibilla Aleramo nos ofrecen la posibilidad de analizar las complejas relaciones entre los diferentes géneros que se agrupan bajo la etiqueta de autobiográficos. Ya desde su debut literario con Una donna, Sibilla parece determinada a hacer literatura con materiales provenientes de su historia personal, por esa filosofía que la acompañó hasta el final de sus días, que consistía en una identificación total entre existencia y literatura.

Dejando a parte la producción poética y los numerosos epistolarios, la novela autobiográfica constituye sólo la primera etapa de una serie de modelos formales en los que vida y escritura se confunden: autobiografía lírica (Il passaggio, Il frustino), novela epistolar (Amo dunque sono), libro de apuntes y galería de retratos (Gioie d'occassione) culminará en la redacción de un diario íntimo que se extiende durante los últimos veinte años de su vida (Un amore insolito. Diario 1940-1945 y Diario di una donna 1945/ $1960)^{1}$.

Este diario asume bajo numerosos aspectos las características de una auténtica autobiografía, no sólo porque sigue esquemas retóricos propios de este género, sino porque desde el principio se constituye como un texto destinado a un público, contraveniendo la regla del diario, que persigue sobre todo la expresión en lugar de la comunicación y excluye el destinatario, al menos en fase de constitución.

${ }^{1}$ La primera edición del diario aparece en 1945 con el título Dal mio diario, donde se recogen anotaciones de los años 1940-44. La segunda edición es de 1978, que aparece con el título Diario di una donna, y se corresponde a los años 1945-60. Un año más tarde se publica la edición completa de los años 1940-44 con el título Un amore insolito. 
La dimensión comunicativa en la que Sibilla concibe el diario encierra dentro de sí un carácter póstumo, definitivo, que se identifica más con el modelo de la autobiografía entregada a los que han de venir, que con el carácter provisional e inacabado del diario:

Ansia de comunicare con gli altri che è stato il fulcro della mia vita e che, ora tanto più che essa è alla vigilia di spegnersi, vorrei esser certa d'aver inciso nell'opera per il tiempo in cui non ci sarò più ${ }^{2}$.

Esta dimensión condiciona además profundamente la estructura interna del texto, con la hegemonía del narrador sobre al autor-personaje y con una parte introductiva, que asume la función de un incipit donde se establecen las condiciones del «pacto autobiográfico» ${ }^{3}$ con el lector, cuya presencia produce una coherencia, que a pesar de la fragmentación cronológica típica del diario, se manifiesta mediante una organización interna del texto, en el que Sibilla interviene a distancia temporal con relecturas, correcciones, censura o inclusión de notas a pie de página, aportando aclaraciones y precisiones encaminadas a una lectura unitaria del diario.

La intromisión se hace necesaria en función de la referencia extratextual a la vida del autor, cuya figura predomina con respecto al texto que crea, puesto que el interés del lector por la obra autobiográfica está estrechamente ligado al interés que su autor despierta como persona, prescindiendo de la forma en la que éste se expresa.

El predominio del autor se hace más relevante en la medida que el diario prescinde de exigencias estéticas y se constituye como práctica de escritura altemativa, como en el caso de Sibilla. En este sentido la exposición de los motivos que impulsan a la escritura forman parte de la dinámica y de la estructura del texto en la medida que pretenden ser literario, y por otra parten constituyen el control que el «yo» autobiográfico ejerce sobre el lector, llamando su atención sobre hechos o reflexiones significativos, resaltando el valor objetivo y extraordinario de su experiencia.

Es en esta reflexión metatextual donde el diario cede definitivamente su terreno a la construcción de la autobiografía: Sibilla se sirve de un «yo» autobiográfico que hace presente sus intenciones, aduciendo los motivos subjetivos que la impulsan a la redacción de la propia vida ${ }^{4}$.

Siguiendo el modelo que se encuentra con frecuencia en las confesiones o apología, en primer lugar el diario nace de un estímulo externo, de la iniciativa de otra persona que no es el autor pero que ejerce su influencia sobre él. En nuestro caso es el poeta Franco Matacotta, unido sentimentalmente a la autora, el que le propone la redacción e inspira las páginas del diario, al que Sibilla se somete como una especie de obligación a la tarea de escribir, concibiéndolo como una desviación temporal de la obra que no logra componer por falta de inspiración:

${ }^{2}$ Cfr. Sibilla ALERAMO. Un amore insolito. Diario 1940-45. Feltrinelli, Milano 1979.

${ }^{3}$ La terminología pertenece a Ph. LEUJENE. Il Patto autobiografico. Il Mulino, Bologna 1986.

${ }^{4}$ Ver Toni CERUTTI. Per una tipologia dell'io autobiografico, en L'Autobiografia il vissuto e il narrato. «Quaderni di retórica e poetica», n. 1, Liviana, Padova 1986. 
Allora, che cosa scrivere in questo diario? Notare l'arrivo di qualche sua rara lettera, notare lo scorrere uguale della mia giornate nella solitudine della soffitta, qualche invito dai pochi amici rimasti in città, qualche lettura....

Es la presencia de Franco la que dirige en cierto sentido la concepción y la composición del texto según un modelo literario, que justifica el proyecto autobiográfico:

Egli afferma che non ho mai, salvo nel mio primo remotissimo libro, e per i miei primi anni, data la sensazione reale di quel ch'io sono stata, il valore, il peso, la sostanza del tempo in cui ho vissuto ${ }^{6}$.

La dinámica de la relación entre ambos, que se basa en un «destino di poesia» en común, establece además la valencia ideológica, donde la literatura dirige la vocación de la propia existencia:

Nella stanza sottostante, Franco intanto spera ch'io lavori (...) Per contentarlo, tanto mi commove nell'intimo questa sua brama di vedermi riprendere quella che io stessa per tanto tempo ho ritenuta mia suprema missione... ${ }^{7}$.

Por otra parte, Franco es también el destinatario inmediato, el lector privilegiado, como sucede en la autobiografía religiosa, se convierte en el supervisor del texto leyéndolo a medida que se hace, juzgándolo, revisándolo, censurándolo y llegando a intervenir en su redacción:

Ho riletto sotto la suggestione della lettera di Franco, e anche di quella di Mucchi: entrambe parlano di «autobiografia». Ma Franco, che conosce questo mio attuale diario, che cosa pensa precisamente? Ch'io lo continui, e da esso «risalga al passato» o, lo tronchi, e inizi da domani una narrazione nuova, in quest'aura di lontananza, con un tono più unito, più fermo?... ${ }^{8}$.

Finito di correggere le bozze del Diario. Anche Franco, dopo di me, le ha revisionate 9 .

La motivación externa a la escritura no excluye toda una serie de motivos personales que son consecuencia directa o indirecta del carácter testamentario y póstumo del que hablábamos al principio, que desde el punto de vista pragmático podemos agrupar en torno a cuatro categorías ${ }^{10}$.

${ }^{5}$ S. ALERAMO. Un amore insolito, cit., p. 83.

${ }^{6}$ Ibidem., p. 9.

${ }^{7}$ Ibidem., p. 3.

${ }^{8}$ Ibidem., p. 80.

${ }^{9}$ S. ALERAMO. Diario di una donna. Inediti 1945-1960. Feltrinelli, Milano 1978, p. 60.

${ }^{10}$ Sobre la clasificación de los motivos que caracterizan la autobiografía consultar Franco DINTTMO. L'Autobiografia moderna. Collana di studi di letteratura comparata, n. 3, Carrucci, Roma 1989. 


\section{El testimonio}

En el análisis y consideración que Sibilla hace de sí misma, muchas veces, adopta la perspectiva del papel que ha desarrollado o desarrolla en el contexto histórico e intelectual que está viviendo, por una necesidad inferior de clarificación de la propia posición en el mundo, que encierra además dentro de sí un carácter de ejemplaridad:

L'ho scritto totalmente per me, mentre non mi sentivo il vigore della creazione: per me a liberazione, e forse, un poco anche per lasciare una testimonianza quasi quotidiana della mia anima, pero consegnare all'avvenire il ricordo di quel che è stata la vida intima di una donna poeta, in anni crudeli per il mondo... ${ }^{11}$

$\mathrm{El}$ «yo» autobiográfico es consciente de la singularidad de sus experiencias, que, precisamente por su carácter excepcional y único poseen un inestimable valor $\mathrm{y}$, en consecuencia, son dignas de ser transmitidas:

Come, como ho potuto sopportar tanto, tanta gente, tanta passione tante reazioni tanto pensiero e tanto lavoro, senza tregua mai, mai mai? Nessuno, fra quanti ho incontrati e conosciuti, nessuno, no, ha accumulato una tal somma di esperienza, neppure i più grandi, fra tante difficoltà e ostilità, sempre risorgendo più forte più implacabile più creativa, restando pur sempre donna, fedele al proprio mito femmineo... ${ }^{12}$.

\section{La apología}

Dejar testimonio está estrechamente ligado a la apología, que en el diario sigue los dos presupuestos fundamentales de toda autobiografía: el primero, que sólo el autor, puede conocer la verdad sobre sí mismo, las razones de su comportamiento, y su auténtica historia, por lo tanto mediante la escritura se intenta restablecer la verdad, combatir la reconstrucción parcial o inexacta de la propia imagen:

Dice che circola nel mondo un'immagine di me parziale, imperfetta, e perfino falsa. Di me alla quale s'è sempre rimproverata la sincerità eccessiva, urtante ${ }^{13}$.

El segundo consiste en la demostración de la coherencia y permanencia del «yo» a través del tiempo, que se presenta en una relación de continuidad consigo mismo a pesar de los cambios y las visicitudes de la vida:

\footnotetext{
${ }^{11}$ S. ALERAMO, Un amore insolito, cit., p. 436.

${ }^{12}$ S. ALERAMO, Diario di una donna, cit. p. 407.

${ }^{13}$ Ibidem., p. 9.
} 
Ma Ibsen mi era come il simbolo della mia coscienza, mai rinnegata, al tempo in cui avevo lasciato marito e figlio per essere «in pace con me stessa» come scrissi nella chiusura di Una donnal ${ }^{14}$.

La fidelidad consigo misma se nutre en Sibilla de modelos culturales, pasa a través de lecturas donde escritura y vida se apoyan mutuamente, encuadrando su comportamiento individual en una dimensión mítica de carácter universal, en la que la autojustificación personal se expresa en términos religiosos de conversión y nacimiento a una nueva vida, de dogma que requiere, como hemos visto, el apostolado y el testimonio:

Ibsen giungendo laggiù fino alla mia tragica coscienza, non mi prometteva gioia, ma solamente l'accordo con me stessa: e chiamandomi ad assumere intero il peso del mio atto, e ad ubbidire ferocemente alla mia legge, fece si che io mi trovassi poi ad esistere come una persona nuova, una nonata adulta, un «isola, una volontà cupa e rigida sotto l'incantata e tenera apparenza ${ }^{15}$.

La coherencia e integridad del «yo» resaltan aún más en las dificultades que encuentrá para afirmarse, están unidas a un sentimiento polémico, que adopta tono de resentimiento por la situación de precariedad económica en la que vive sin recibir una compensación material adecuada, y sobre todo, por la falta de reconocimiento de su obra:

La sua arte, (habla de Ada Negri) se tale è, è stata agli antipodi della mia, ed è cosa ovvia che abbia oggi la suprema consacrazione ufficiale, mentre io rimango e quasi certamente rimarrò sempre non accettata al gran pubbico borghese, detestata dal clero, una rivoluzionaria della quale è meglio tacere ${ }^{16}$.

La necesidad de afirmación del «yo» ante un ambiente que le es hostil y no reconoce sus méritos, se hace más necesaria desde la posición apartada que Sibilla ocupa un respeto al ambiente literario, de no participación ni adaptación a las nuevas tendencias estéticas de su tiempo:

Non si accetterà mai di premiare a festeggiare, in Italia, chi ha scritto una donna. Chi ha avuto l'esistenza che ho avuta io, per quanto scontata con lagrime e sangue, per quanto documento formidabile di forza, di resistenza, di amore, di fede, e, sì, di purezza linteriore. Mai, Forse, dopo morta. Dopo molto tempo dopo la mia morte, forse ${ }^{17}$.

${ }^{14}$ Ibidem., p. 41.

${ }^{15} \mathrm{~S}$. ALEDAMO, Un amore insolito, cit., 15.

${ }^{16}$ Ibidem, p. 9.

${ }^{17}$ S. ALEDAMO, Diario di una donna, cit., p. 189. 


\section{La búsqueda de una identidad}

La polémica apologética tiende a la conquista de un espacio subjetivo en contraposición a los demás y constituye una forma negativa, en el sentido de contraste y oposición de la búsqueda de la propia identidad, en cuya base figura precisamente el aislamiento y la pérdida del sentimiento de «pertenencia»:

Come son sola, come son sola, spiritualmente, senza nessuno a cui chieder consigli, con cui comunicare i mei stadi d'animo... ${ }^{18}$.

Por otra parte la fuga de la sociedad se manifiesta en la necesidad de refugiarse en la escritura como compensación, como espacio donde se manifiesta la verdadera identidad, en cuyo mecanismo se desvela, como en un sueño, el «yo» más íntimo y oculto:

Ecco, anche la frase che ho ora scritta potrebbe essermi stata dettata in sogno... non sto forse tentando di svelare me a me stessa?... ${ }^{19}$.

E le migliaia di pagine che ho scritto per narrarmi, per spiegarmi ${ }^{20}$.

La búsqueda de la identidad personal coincide además en Sibilla con la búsqueda de una identidad histórica como mujer, forma parte de una búsqueda existencial y metafísica:

La donna non è mai stata una vera e propria individualità: o si é adattata a piacere all'uomo, non solo fisicamente ma anche moralmente, senza ascoltare $i$ comandi del suo organismo e dalla sua psiche; o gli si è ribellata copiandolo, allontanadosi ancor di più della conquista del suo io ${ }^{21}$.

En el segundo diario, a partir de la ruptura sentimental con Franco Matacotta y la adhesión al Partido Comunista, Sibilla sufre una crisis existencial a raíz de la cual reconstruye la propia identidad sobre nuevas bases. La escritura autobiográfica supone entonces un movimiento positivo de reconciliación y reconocimiento, recoge el momento crucial cuando el «yo» del pasado parece morir para dejar paso a esta nueva identidad que comprende, asumiéndolos, todos los aspectos de la anterior:

dovrei, paragonando quei venti, trenta, quarant'anni, a questi ultimi dieci, dalla guerra in qua, e soprattutto a questi ultimi sette, dopol'adesione al partito, dovrei provare una certa fierezza: per questa mia vecchiaia che si alimenta unicamente dell'amore per l'Idea, e che trova giorno e notte il coraggio di proseguire sentendosi necessaria, nonostante tanta stanchezza, necessaria nella lotta insieme ai compagni...22.

\footnotetext{
${ }^{18}$ Ibidem., p. 283.

${ }^{19}$ Ibidem., p. 130.

${ }^{20}$ Ibidem., p. 21.

${ }^{21}$ Ibidem., p. 317.

${ }^{22}$ Ibidem, p. 327.
} 


\section{El sentimiento del tiempo}

El diario de Sibilla es una obra de madurez (lo empieza a los 54 años) y naturalmente era ya una escritora famosa, dos condiciones que orientan el diario hacia la autobiografía retrospectiva, aunque paralelamente la reconstrucción de la vida, a través de la objetivación escrita, se convertirá en forma de supervivencia en el futuro.

La reconstrucción adopta dos recursos retóricos: primero la recuperación del tiempo perdido, que se expresa en la referencia a la infancia, que constituye el elemento inicial en la autobiografía y que en el diario se presenta como momento de formación ideológica y proporciona, por tanto, el dato de la génesis de la propia individualidad en el tiempo:

A mio padre, figlio di um mazziniano ardente, lo avevo ricevuto quel senso di sincerità, d'indipendenza, di coraggio.... ${ }^{23}$.

Segundo, con la presentación de una línea que dirige la trayectoria de su vida, donde se puede detectar una trama, oculta, un destino que en Sibilla coincide, como habíamos visto, con el «destino di poesia»:

Ho voluto bene ad ogni mio libro (...) perché in ciascuno, più o meno riuscito dal punto de vista dell'arte, ho sempre trovata spressa la verità profonda dell'anima mia: ciò che all'anima mia ha permesso sempre di sopravivvere a tanta faticata e straziata vita (...) Non vanità, anzi riconoscenza, direi al mistero che $\mathrm{m}$ 'ha concesso di sprimere la mia umanità, nei limite della mia forza, umilmente ma con appassionato amore ${ }^{24}$.

La exposición de los motivos existenciales se dejan sentir más en las anotaciones de los últimos años con el aproximarse de la vejez y de la muerte: combatir el olvido, dejar memoria de sí, transcender el propio tiempo, someterse al juicio de la historia, dar un sentido a la vida ya vivida:

Questo anelito, tra commovente e puerile, di salvare dal barato, dal nulla, qualcosa di ciò che fu vita, qualche eco, qualche accento! Salvare per qualche decennio ancora, se non per i secoli25.

El diario recoge y dispone las pruebas de una existencia, que intenta salvarse a través de la escritura: son cartas, apuntes, notas, documentos, páginas de diarios escritos en juventud, que Sibilla destina a futura memoria:

decido d'inserire qui la lunga lettera da Sorrento a Gerace, incollerò le paginette per evitare la fatica della copiatura, (sono così stanca). Sarà in quest'estate 1931 del mio diario, una parentesi singolare per gli eventuali lettori dell'avvenire ${ }^{26}$.

\footnotetext{
${ }^{23}$ Ibidem., p. 14.

${ }^{24}$ Ibidem., p. 230.

${ }^{25}$ Ibidem., p. 138.

${ }^{26}$ Ibidem., p. 283.
} 
Mediante estas cuatro categorías el «yo» autobiográfico pretende demostrar su identidad y todo su valor con respecto a la sociedad mediante efectos comparativos, repetitivos, conclusivos y descriptivos que contribuyen a formar la imagen de un autorretrato, que se entrega a los póstumos y a la vez se dirige a los contemporáneos, 10 que nos conduce de nuevo a la dimensión pragmática del texto autobiográfico, cuyos recursos se encaminan a la persuasión y captación de reales o posibles lectores. 